\title{
Monitoring Our Rivers and Streams
}

All of life depends on water, and all of us are citizens of a watershed. Our activities and the ways we use our water resources and the land adjacent to the water affect the quality of our drinking water, our recreational opportunities, and the health and diversity of aquatic plants and animals. Our activities also affect whether our rivers and streams will continue to be beautiful places to visit and vistas to contemplate.

In this publication, you'll find information about watersheds and about monitoring the quality and quantity of surface-water resources. You'll learn how the U.S. Geological Survey (USGS) monitors streamflow and surface-water quality across the Nation and how USGS information can help you learn more about your water resources-whether as a citizen of your watershed or an active citizen monitor.

This publication focuses on surface water, but keep in mind that surface water and ground water are interconnected. USGS also monitors the flow and quality of ground water, and investigates surface- and ground-water interactions.

\section{USGS and citizen monitoring}

The water quality of a nearby stream, a watershed, or a large river system can be enhanced only by collecting good information about conditions and by responding - most effectively at

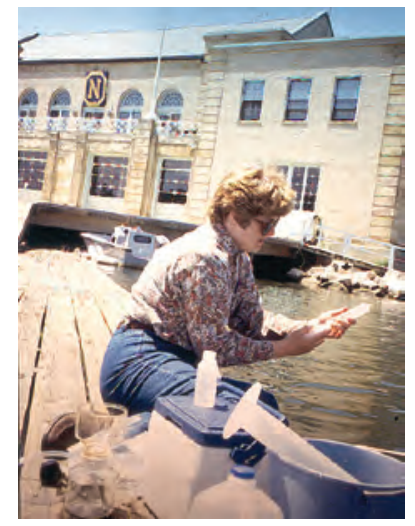

A citizen monitor with Alliance for Chesapeake Bay prepares to collect water samples near the U.S. Naval Academy, where submerged aquatic vegetation is being replanted. Some citizen data were used in USGS studies of these aquatic plants, which are vital to the Bay's health. (Photo by Bob Murphy, Alliance for Chesapeake Bay.) the local level - to that information. Informed citizens of a watershed often are in the best position to identify priority water issues and to understand the political, social, and economic context in which those issues are addressed. USGS works with citizen monitors in many watersheds across the Nation. Typically, watershed associations, such as the Alliance for Chesapeake Bay and Watershed Committee of the Ozarks, plan and conduct the activities of citizen monitors. Citizen monitoring enhances the monitoring conducted by USGS and other federal and state agencies by filling in geographic gaps or by increasing the frequency of sampling. Information collected by citizen monitors can also help USGS and other water-resource agencies know where to focus their broader data-collection activities and analysis. In turn,

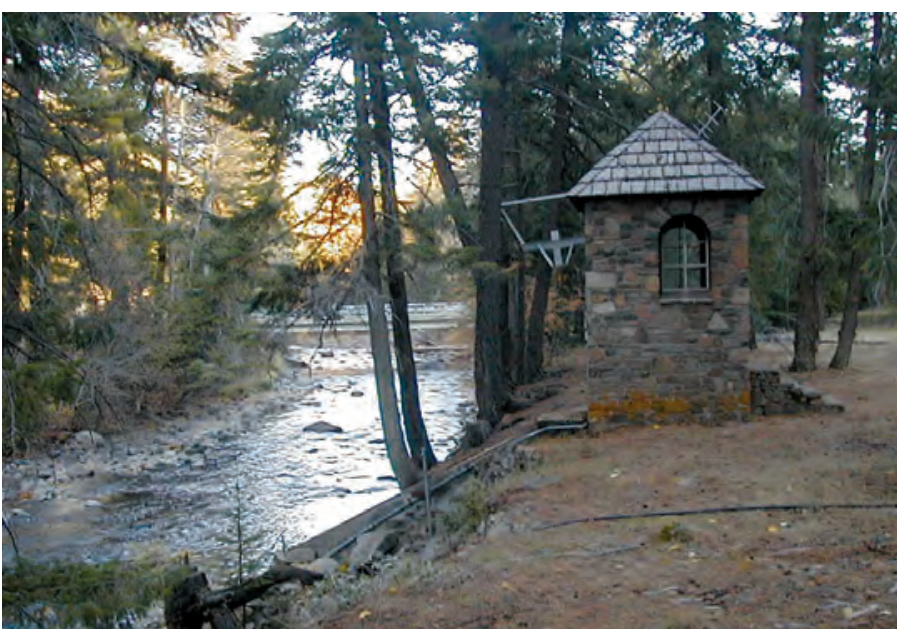

Stream-gaging station on the American River near Nile, WA (USGS Station No. 12488500), one of more than 6,600 across the Nation with real-time streamflow data. (Photo by Van Wilson, USGS.)

hydrologists from USGS and other agencies often train citizens during "side-by-side" data-collection activities.

To learn about USGS monitoring activities in your state, call or e-mail the USGS representative. A list of contacts is at water.usgs.gov/district_chief.html.

\section{Understanding your watershed}

Natural features, such as topography, define watersheds-land areas that receive rain or snow and drain to specific surfacewater bodies, such as streams, rivers, lakes, reservoirs, bays, or oceans. Both natural and human-induced conditions within the watershed are reflected in the quality of the surface water.

More and more, water-quality management and policies are being developed in terms of the watershed, rather than being couched in terms of cultural boundaries, such as counties and states. While many federal and state agencies focus on the larger river systems and associated watersheds, local agencies and citizens usually are concerned with the smaller watersheds where they live. Because the smaller watersheds are "nested" within the larger river networks, and because many watersheds cross jurisdictions, successful watershed management requires that everyone work together-citizens and water-resource professionals, and local, state, interstate, and national stakeholders.

A standardized watershed classification system - the Hydrologic Unit System — was developed in the mid-1970s by USGS under the sponsorship of the U.S. Water Resources Council. The goal was to delineate and map hydrologic boundaries and enable a variety of organizations and programs to share information and coordinate management of watersheds. 
Hydrologic units are a topographically defined set of watershed boundaries, organized in a nested hierarchy by size. The system divides the Nation into 21 regions (representing some of our largest rivers, such as the Missouri, Susquehanna, and Columbia Rivers), and progressively smaller sub-regions, accounting units, and cataloging units. Each cataloging unit is assigned an 8-digit code (its hydrologic unit code, or HUC) having two digits for each of the four levels.

The 8-digit HUCs are used widely, such as in the U.S. Environmental Protection Agency (EPA) Water Information Network (described below). The geographical area of the cataloging units is often too large, however, for management at the local level, such as for land-use planning. Therefore, USGS, U.S. Department of Agriculture, EPA, and other federal agencies and interested states are in the process of subdividing cataloging units into watersheds (average size 40,000-250,000 acres) and sub-watersheds (10,000-40,000 acres). For information on HUC maps and watersheds in your State, call 1-888-ASKUSGS or go to water.usgs.gov/GIS/huc.html.

\section{A monitoring protocol}

Monitoring is necessary to ensure that our waters can continue to support the many different ways we use these resources and to track whether protection and restoration measures are working. The information gained from monitoring helps with prioritizing the issues to be addressed and choosing the geographic areas in which to concentrate, thus helping to ensure cost-effective water-resource management.

Effective monitoring is regular, long term, and includes biological, physical, and chemical measurements.

- Why regular measurements? Taking a single waterquality measurement will not indicate how the property varies over time. For example, if you measure the $\mathrm{pH}$ of a stream and find that it is 5.5, you might think that the water is acidic because of a water-quality problem. But a $\mathrm{pH}$ of 5.5 might be "normal" for that stream. Similarly, one person's normal body temperature may be about 97.5 degrees, but another person's is right at 98.6. As with human temperatures, if the $\mathrm{pH}$ of a creek begins to change, then something might be affecting the water, and possibly, the water quality. So, often, the changes in water measurements are more important than the actual measured values.

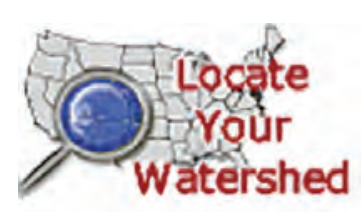

To locate and learn about your watershed, go to EPA's Water Information Network at www.epa.gov/win/ and click on "Surf Your Watershed," then on "Locate Your Watershed."

Search by map, stream name, zip code, county, Tribal nation, or other geographic names to find your watershed and its hydrologic unit code (HUC). For example, if you live in Tennessee and your zip code is 37919 , you live in the Watts Bar Lake Watershed, which is HUC 06010201.
- Why long term? Long-term data collection, using consistent and comparable methodology, is critical to identify trends or patterns, to try to find out: "Are things getting better or worse?" Water quality is constantly changingduring the day, from day to day, from season to season, and from year to year. To distinguish real trends from short-term fluctuations, we need consistent and systematic information over the long term. This is also necessary for evaluating environmental strategies and choosing the most cost-effective strategies for the future.

- What does biology have to do with water quality? Biological communities are indicators of stream quality. Organisms such as algae, invertebrates (insects, worms, and clams), and fish have a wide range of sensitivities to physical and chemical changes in their habitat. For example, increasing algae populations often correlate with higher concentrations of nutrients (nitrogen and phosphorus). Other indicators of degraded water quality are a preponderance of worms and midges, which are "tolerant" of pollution, or a fish community that is not diverse and abundant or that is composed of non-native species. Biological communities also reflect the overall health of a watershed. Physical processes, such as deforestation and fires, can alter stream habitat, hydrology, and stream temperature and can quickly degrade biological communities before nutrients and other contaminants reach levels that can degrade these communities.

- What does water quantity have to do with water quality? The quantity of streamflow (also called "discharge") is an important factor in determining water quality and, thus, in interpreting water-quality data. The potential effects of contaminants on drinking-water supplies and aquatic habitats depend largely on the amount of water flowing in streams. You may have heard the outdated adage that "dilution is the solution to pollution." More flow, however, usually means that rivers and streams are carrying a greater magnitude of contaminants and sediment, in part because of overland runoff. When waters carrying these increased loads reach gulfs and bays, aquatic plants and animals can be greatly affected, particularly if this occurs during the critical life cycles of these organisms.

\section{A "hydrologic context" for your monitoring data}

Information from USGS monitoring can help you understand more about the significance of the conditions you observe or measure in your watershed. Several characteristics of USGS monitoring provide this "hydrologic context":

\section{Monitoring is at different scales and in different environmental settings}

USGS investigates local issues and trends in a particular stream or in a particular county, as well as larger regional systems, such as the Mississippi River Basin. Methods of sampling and analysis are uniform, and monitoring is done at sites that are 
representative of watersheds across the Nation, so that comprehensive assessments can be made at larger, even national, scales. This multi-scale approach helps to determine if certain types of water-quality issues are isolated or pervasive, and allows streams and rivers to be compared to those in other geographic and environmental settings. Therefore, the data can help answer questions like-

- Is the $\mathrm{pH}$ in my stream typical of streams in the Atlantic Coastal Plain?

- Are other streams in the arid west experiencing elevated salinity?

- Is a nitrate concentration above 5 parts per million commonly found in other watersheds?

\section{Monitoring is regular and long term}

USGS has been collecting data for more than a century at some of its monitoring stations. Long-term data collection creates a set of baseline data that can be used to assess the significance of observed changes. For example, collecting data on our water resources over the long term helps answer questions like-

- How high will streams rise if my area experiences a 100-year flood?

- Did implementation of stream buffers and other restoration practices work?

- Are streamflows in this watershed at historically low or high levels?

\section{Nationwide streamflow data are available on the Web}

Currently, USGS regularly collects streamflow data at more than 7,200 sites ("gaging stations"). Most of the stations are funded and operated in cooperation with other federal agencies, such as the U.S. Army Corps of Engineers, and with state, Tribal, county, and municipal agencies, who use these data for making decisions such as when to withdraw water from rivers or reservoirs and whether to permit discharge of treated wastewater. Provisional data from more than 6,600 of these stations are available in "real time" (updated at intervals of 4 hours or less) at waterdata.usgs.gov/nwis.

Access to streamflow data allows for more accurate interpretation of water-quality data. An observed trend in water quality-for example, increasing concentrations of a contaminant in a stream over a six-month period-may indicate an actual water-quality change or may be the indirect result of differences in the distribution of flow volumes when the water samples were collected.

\section{Nationwide water-quality data are available on the Web}

USGS collects samples from streams across the Nation and analyzes for chemical, physical, and biological properties of water, sediment, and tissue. Data are collected for investigations that range from national in scale, such as the National Water-Quality

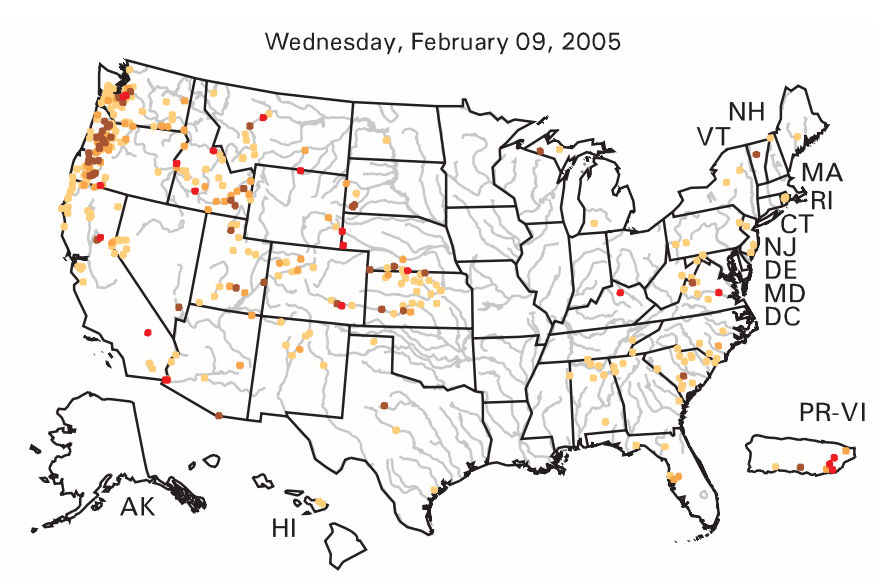

This map highlights areas experiencing dry conditions over the past 7 days, from below-normal streamflows (lightest colored dots) to "extreme hydrologic drought" (red dots). "Normal" streamflow is defined in the context of conditions that have been recorded at a streamflow-gaging station at the same time of year over the past 30 or more years. Maps like this one, and other maps and graphs of streamflow conditions are available on the USGS WaterWatch Web site at water.usgs.gov/waterwatch/.

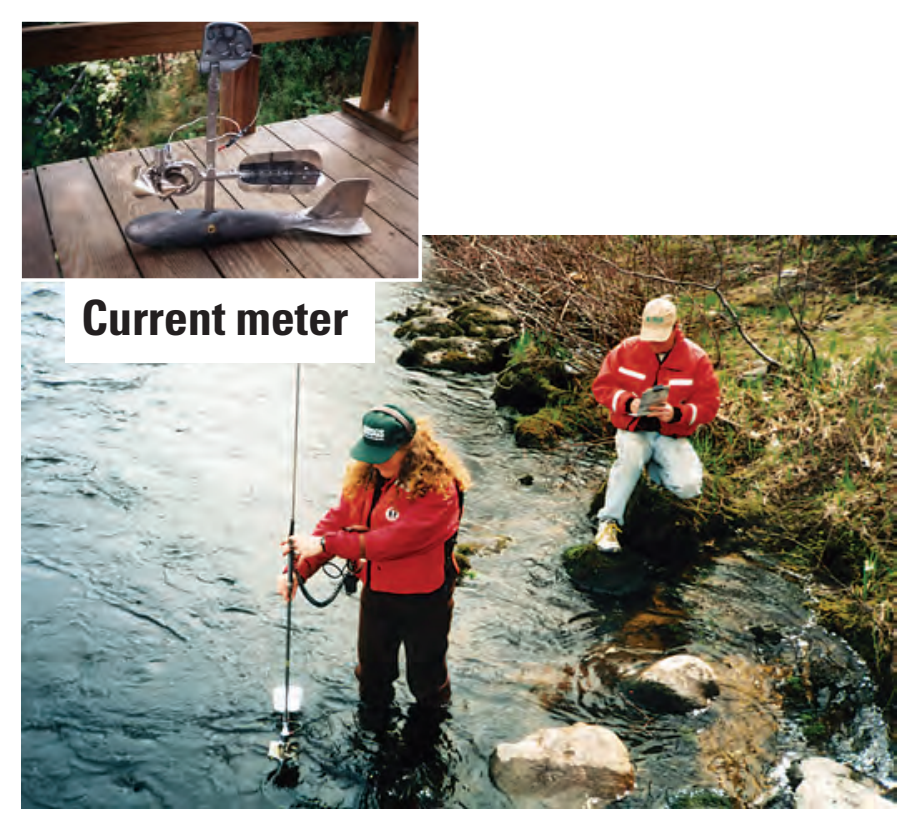

Technicians are measuring discharge, the volume of water passing a given stream cross section in a given period of time (reported as cubic feet per second, or $\mathrm{ft}^{3} / \mathrm{s}$ ). Another type of data collected to determine streamflow is stage (or "gage height"), the height of the water above an arbitrary reference point set at the gaging station. Stage measurements are continuously recorded by equipment inside a gagehouse located on the stream bank and relayed via telephones or satellites to USGS offices. It isn't practical for people to make continuous discharge measurements, so daily discharge values (provisional "real-time" values reported on the Web) are computed on the basis of a mathematical relation between the river's stage and discharge. (Photo by Michael Coakley, USGS.) 
Assessment Program (NAWQA), to studies in small watersheds. Typical field measurements (made directly in the stream or on the streambank) include $\mathrm{pH}$, water temperature, dissolved oxygen, and turbidity.

Other field measurements include specific conductance (conductivity), an indirect indicator of dissolved minerals, acids, and metals in the water; and alkalinity, an indicator of water's ability to neutralize acids and keep the $\mathrm{pH}$ constant. Currently, selected field measurements are available in real-time from more than 1,100 USGS sites at waterdata.usgs.gov/nwis/qw.

Other chemical measurements-such as analyses for concentrations of major ions, nutrients, trace elements, pesticides, volatile organic compounds, radioactive chemicals, and organic wastewater contaminants - are made in the laboratory. The USGS National Water-Quality Laboratory in Denver, Colo., specializes in environmental analytical chemistry, and features standardized laboratory methods and quality-assurance and quality-control protocols. In addition, the laboratory methods can detect concentrations at very low levels-commonly 10 to 1,000 times lower than the EPA standards and guidelines. These sensitive methods allow for an early detection of potentially harmful contaminants before they reach levels of concern, and allow for trends to be detected for constituents that are difficult to measure.

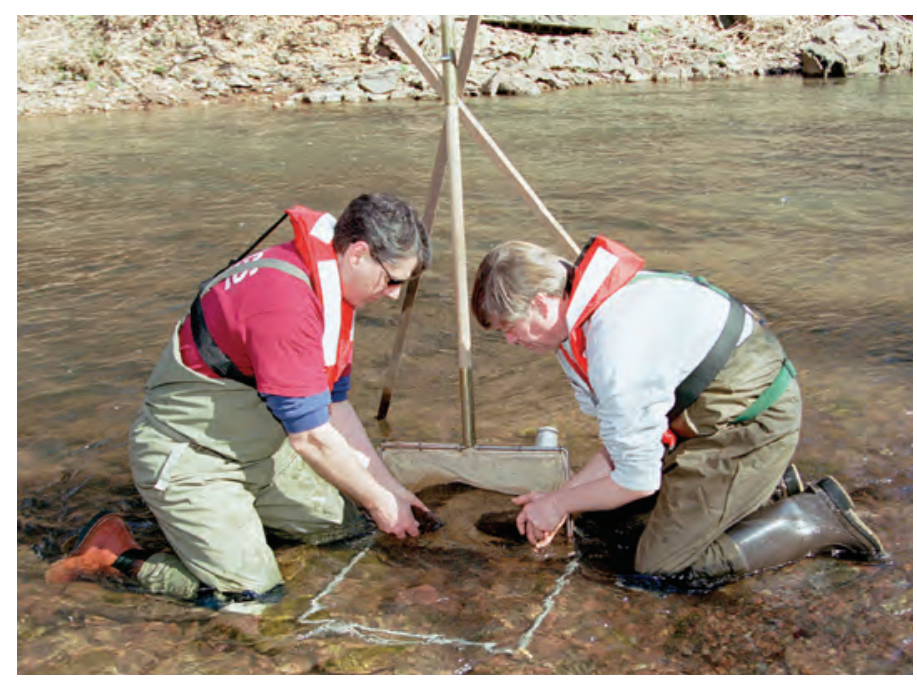

Biologists with the USGS National Water-Quality Assessment (NAWOA) Program are collecting benthic (bottom-dwelling) invertebrates for analysis. USGS also monitors for concentrations of total coliform bacteria and viruses; fish-tissue contaminants (such as mercury, DDT, and dioxin); and algae. (Photo by Denis Sun, USGS.)

\section{USGS monitoring is for assessment only}

USGS has no regulatory responsibilities and focuses on evaluating the entire resource, which may be a source of drinking water as well as of water used for industry, irrigation, and recreation. USGS water-quality data thereby complement much of the data collected by the States and by EPA, which focus on monitoring for compliance with regulations.
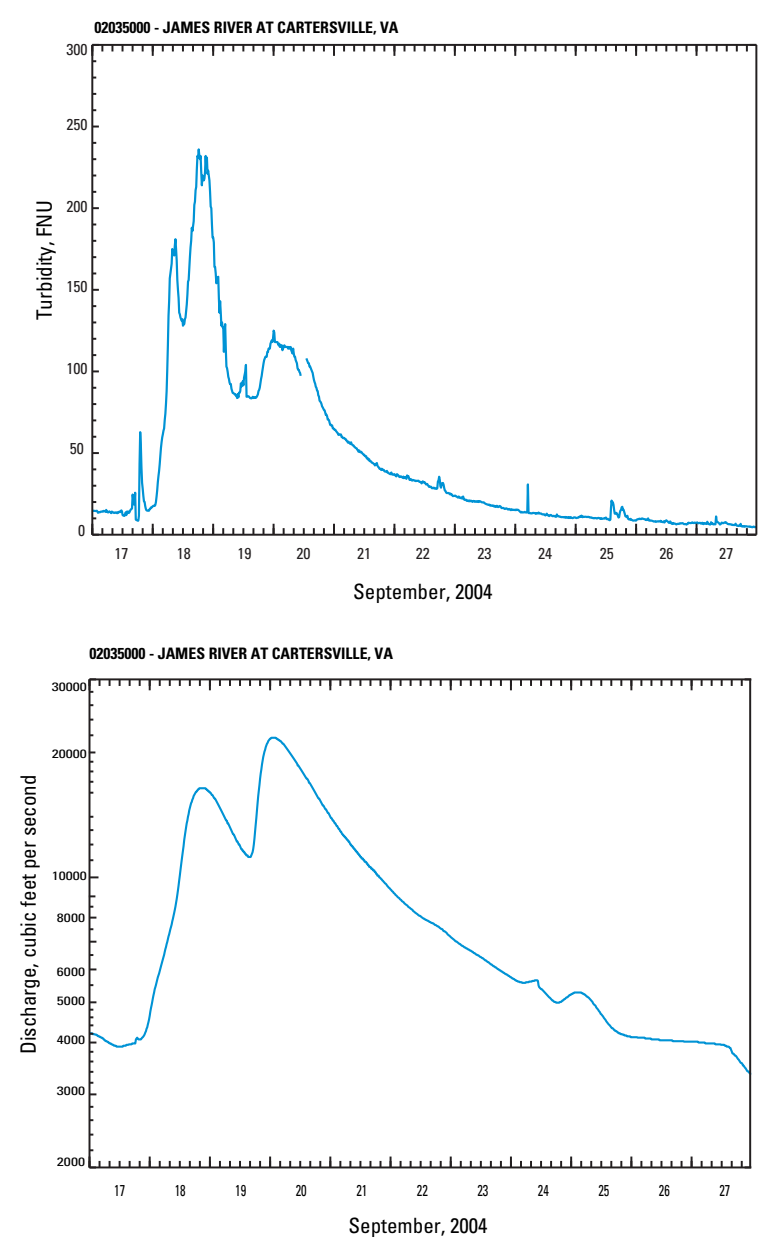

Graphs of real-time discharge values can help you decide if it's a good time for an outing on the river. Discharge data also help with interpretation of water-quality data. For example, an increase in turbidity values (top graph) corresponded with increasing streamflow (bottom graph) at the James River at Cartersville, VA, gaging station in September 2004. This station is one of more than 1,100 across the Nation with real-time data on both water quality and water quantity.

\section{Visit water.usgs.gov for access to online maps, data, and reports, including:}

-WaterWatch for maps and graphs of streamflow conditions

- NWISWeb (National Water Information System) Water

Data for real-time and historical water data

- Publications, including USGS Fact Sheets (short, nontechnical reports)

By Martha L. Erwin and Pixie A. Hamilton

Layout and design by Phillip J. Redman

\section{For printed reports and maps}

Call 1-888-ASK-USGS

Or, write to:

USGS, Information Services

Box 25286, Denver Federal Center

Denver, CO 80225

Or, fax requests to (303) 202-4693 